\title{
Short communication: Effects of dairy calf hutch elevation on heat reduction, carbon dioxide concentration, air circulation, and respiratory rates
}

\author{
D. A. Moore, ${ }^{1}$ J. L. Duprau, and J. R. Wenz \\ Department of Veterinary Clinical Sciences, College of Veterinary Medicine, Washington State University, Pullman, WA 99164
}

\begin{abstract}
Heat stress affects dairy calf welfare and can result in morbidity, mortality, and lower weight gain. The purpose of this project was to evaluate the effects of elevating the back of plastic calf hutches on measures of ventilation and heat stress. A total of 15 calves housed in individual hutches were enrolled, with each calf hutch serving as its own control. Heat, humidity, carbon dioxide, and wind speed were measured inside each hutch and the observations were compared with external measurements over two 24 -h periods; 1 period without and 1 with hutch elevation. Respiratory rates were measured in the morning and afternoon as an indicator of the degree of heat stress experienced by calves with and without elevation of the hutch. When the hutch was elevated, internal hutch temperatures were cooler than external temperatures, hutch carbon dioxide levels were lower and respiratory rates were lower, particularly comparing the afternoon observation periods.
\end{abstract}

Key words: calf, calf hutch, heat stress

\section{Short Communication}

Heat stress in preweaned calves can result in high mortality and morbidity, affects calf welfare, and can negatively affect performance by decreasing appetite and daily weight gain (Broucek et. al., 2009), resulting in increased age at puberty and age at first calving (Tyson, 2011). In a follow-up study of associations of calf-rearing practices with subsequent first lactation, high humidity and temperature created an environment that increased heifer age at first calving (Heinrichs et al., 2005), a known economic cost to the dairy producer. The incidence of heat stress in calves may be related to the type of housing. Prefabricated plastic hutches are a widely favored method of housing dairy calves because they are durable, portable, easy to clean, and allow producers a cost-effective way to house calves

Received January 31, 2012.

Accepted March 12, 2012.

${ }^{1}$ Corresponding author: damoore@vetmed.wsu.edu individually. However, many currently-available plastic hutches can average 5 to $10^{\circ} \mathrm{C}$ higher than wooden ones (Lamb et al., 1987). Even with open ventilation slits or windows, airflow through many hutches is suboptimal, allowing heat, humidity, and carbon dioxide to accumulate (Lammers, et al., 1996).

The thermoneutral zone is narrower for young calves compared with adult cows, with an upper end of normal at about $29^{\circ} \mathrm{C}\left(84^{\circ} \mathrm{F}\right)$ and heat stress considered to occur at temperatures greater than $32^{\circ} \mathrm{C}\left(90^{\circ} \mathrm{F}\right)$ and $60 \%$ humidity (Neuwirth et al., 1979; Gebremedhin et al., 1981). Due to their reduced ability to properly thermoregulate, younger animals are at increased risk for heat stress (Hill et al., 2011). One often-used indicator of heat stress in cattle is respiratory rate. The normal range of housed dairy calves appears to be 24 to 36 breaths per minute (Radostits et al., 2000). When environmental temperatures exceed the thermoneutral range, the animal must use energy to prevent overheating. If conditions are severe enough, this expenditure of energy may not be enough and the animal is affected by heat stress. Feed intake is reduced, whereas energy costs of homeothermy continue to rise. The energy contributed to increased thermoregulatory effort is drawn from the calf's body stores, which leads to decreased feed efficiency and an impaired immune function (Lammers et. al., 1996). Stott et al. (1976) found higher body temperatures, higher serum corticosteroids, lower serum IgG levels, and a higher mortality rate in calves exposed to higher ambient temperatures. Consideration of these consequences renders managing for heat stress essential.

Environmental factors, including ambient temperature, humidity, and wind speed, are important to consider when trying to mitigate heat stress. Humidity has been correlated to increased airborne bacterial counts in calf housing (Wathes et al., 1984). Ventilation is important for removing moist, heated air and accumulated toxins and replacing it with fresh, drier air. Carbon dioxide serves as an indicator of the level of ventilation (Prill, 2000; De Sousa and Pedersen, 2004). Carbon dioxide is produced by respiration and manure decomposition and can build up in improperly ventilated housing. In well-ventilated housing, carbon 
dioxide levels should be minimal as compared with the environment, which typically averages $350 \mathrm{ppm}$ (Prill, 2000).

For many years, dairy advisors have counseled dairy producers on the use of simple improvements that can help reduce heat stress and improve calf health and performance. Providing shade, good hydration, and proper orientation of hutches to minimize sun exposure are all typical recommendations (Moore et al., 2010). Because evaporative cooling is the primary method of heat dissipation for cattle, hutches should be positioned such that wind speed is maximized and internal humidity minimized. Another suggestion for producers using plastic hutches is to elevate the back of the structure with a concrete block to improve directional airflow (Morrill et al., 1991). This method is natural and cost effective, with no further monetary or labor input required. Recent research has shown that elevation of calf hutches can reduce bacterial counts (Hill et al., 2011), but no evidence exists demonstrating a marked improvement in air turnover, reduction of heat, humidity, or carbon dioxide levels within the hutches. The objective of this project was to investigate whether elevating the back of a plastic hutch makes a measurable difference in any of these factors.

On one commercial Holstein dairy in Washington, 15 hutches housing preweaned heifer calves, ages 5 to $16 \mathrm{~d}$, were used in the trial. The hutches were $1.98 \mathrm{~m}$ long $\times 1.22 \mathrm{~m}$ wide, premolded, plastic hutches $(\mathrm{CH} 1 \mathrm{~A}$; EZ Hutch Inc., Kettlersville, OH), arranged in a single row oriented to the east, placed tight to the ground and bedded with straw. Calves were attached with a $1.83-\mathrm{m}$ chain tether to the interior ceiling of the hutch, which allowed them free access to inside or outside the hutch. The hutches were an average of $1.83 \mathrm{~m}$ apart to minimize contact between calves. Calves were fed whole milk twice daily in buckets and a grass hay/calf starter mix. Water was given twice daily after the milk feeding.

Over the period of June 27 to 29, 2011, temperature and humidity data loggers were installed in the hutches (HOBO data loggers; Onset Computer Corp., Pocasset, MA). The data loggers were housed in a $12-$ $\mathrm{cm}$ section of square polyvinyl chloride (PVC) pipe to prevent tampering. The pipe was attached to the inside of each hutch with duct tape at ceiling level. A data logger was also installed outside (within a PVC pipe and not in direct sunlight) of the empty hutch to gather environmental data. Each data logger was programmed using HOBOware software (Onset Computer Corp.) to $\log$ temperature and humidity every hour for $48 \mathrm{~h}$. The data loggers were installed on the first day at $1725 \mathrm{~h}$ (period 0). The hutches were evaluated 3 times daily for internal and external carbon dioxide, wind speed, and calf respiratory rate at approximately 0700, 1200, and
$1700 \mathrm{~h}$, which correspond to testing periods 1,2 , and 3 , respectively, over each 24 -h period. Each hutch served as its own control and after the initial 24-h control period, each hutch was lifted, and a $20 \times 20 \times 41$-cm concrete block was inserted under the back where it remained for the next $24 \mathrm{~h}$ (Figure 1). Air speed was measured using a hand-held anemometer (Kestrel 3000; Nielsen-Kellerman Co., Boothwyn, PA) externally at the windward (west) side of each hutch by the air vent as well as internally, approximately $30 \mathrm{~cm}$ from the back of the hutch at $30 \mathrm{~cm}$ up from the ground. Carbon dioxide levels (ppm) were measured inside and outside the hutches using carbon dioxide detector tubes and a hand-held air sampler (model no. 8014-400A; Kitagawa America LLC, Pompton Lakes, NJ). The air sample for carbon dioxide was taken $30 \mathrm{~cm}$ above ground level in the center of the hutch. Differences in temperature, humidity, and carbon dioxide levels were calculated for each sampling period for hutches with and without elevation. Respiratory rates were measured via visual observation of flank movements for each calf during an observation period for $15 \mathrm{~s}$ and the number multiplied by 4 to get breaths per minute. Respiratory rates were compared for time periods 1 and 3. Time period 2 was excluded because calves had been handled for paste dehorning just before that observation time on the second day of sampling. The experimental protocol was reviewed by the Washington State University Institutional Animal Care and Use Committee.

Only 10 of the data loggers made recordings. Temperature and humidity fluctuated between 15 and $44^{\circ} \mathrm{C}$ and 15 and $70 \%$, respectively, during the trial (Figure 2). Comparing the differences between the external and internal temperatures at the same time periods, the internal temperature of the elevated hutches tended to be $0.12^{\circ} \mathrm{C}$ cooler than the external temperature, whereas the unelevated hutches tended to be $0.44^{\circ} \mathrm{C}$ hotter, on average $(P=0.06)$.

Prevailing winds during the study period came predominantly from the west and varied widely (hourly data report from the nearest weather station), gusting from $1 \mathrm{~km} / \mathrm{h}$ up to $27 \mathrm{~km} / \mathrm{h}$. With no hutch elevation, air speed in the hutch was initially zero in all areas except within about $10 \mathrm{~cm}$ of the ventilation holes, where air speed averaged $2.1 \mathrm{~km} / \mathrm{h}$ as compared with outside air speed (measured just in front of the ventilation holes) of $3.7 \mathrm{~km} / \mathrm{h}$ (Figure 3). Air speed readings were taken at 2 of the observation periods for each hutch. Once the hutches were elevated, numerous areas within the hutches had measurable air movement, with the greatest found approximately at midline $30 \mathrm{~cm}$ and $30 \mathrm{~cm}$ above floor level at the rear of the hutch. At this point, the average air speed inside the hutches was $6.2 \mathrm{~km} / \mathrm{h}$ and the average wind speed outside was 10.5 


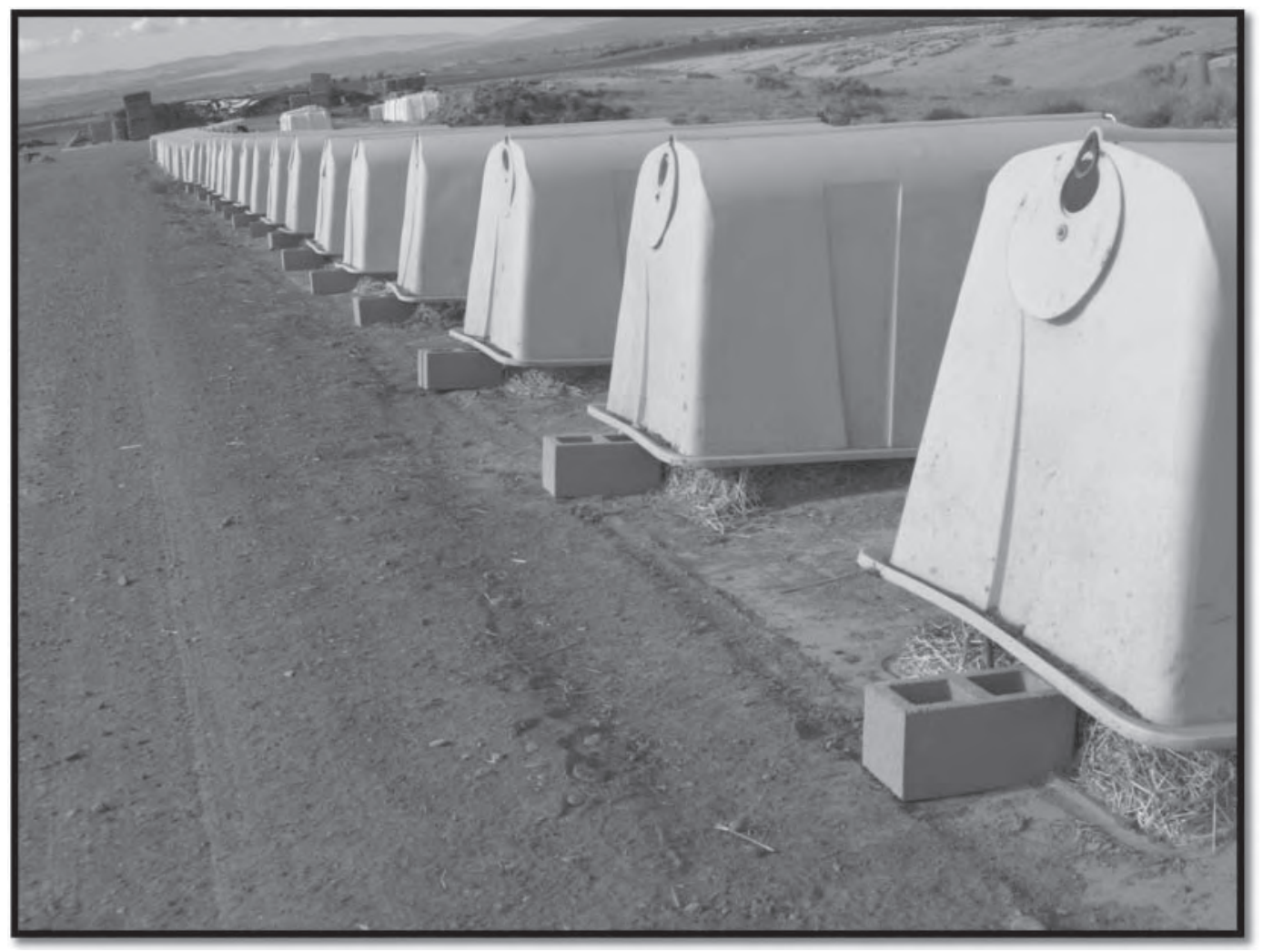

Figure 1. Placement of the concrete block under the plastic calf hutches in a trial of heat stress remediation.

$\mathrm{km} / \mathrm{h}$. The direction of the airflow within the hutch was altered as well. Directional air flow was observed using an aspirator bulb and smoke tube (model 8014-300K; Kitagawa America LLC). The smoke was observed to hang in the air and curled up the walls before eventually flowing out. When the hutch was elevated, air appeared to move more quickly toward the entrance, ventilation hatch, or out around the concrete block.

Carbon dioxide levels were measured at 7 time periods for all 15 hutches housing calves (Figure 4). Outside carbon dioxide levels averaged $483 \mathrm{ppm}$ for all periods (range 400-500). Using a paired $t$-test, at each time period, internal hutch carbon dioxide levels were significantly lower after the hutches were elevated $(P<$ 0.01). However, a significant negative relationship was found between outside wind speed and internal hutch carbon dioxide levels $\left(\mathrm{R}^{2}=0.33 ; P<0.001\right)$, which could be confounding this result, as wind speeds were significantly higher on the day the hutches were elevated. However, the outside carbon dioxide levels were not significantly different across time or treatment periods.

Before respiratory rates were evaluated, calves were observed as to whether they were inside or outside the hutch and whether they were standing or lying. Across the 2 observation periods, $40 \%$ of calves were observed standing outside, $7 \%$ were standing inside, and $53 \%$ were lying inside before the hutches were elevated. After the hutches were elevated, $7 \%$ of calves were observed standing outside, $7 \%$ were standing inside, $83 \%$ were lying inside, and 3\% (1 calf) was lying outside. Lying was strongly associated with being inside the hutch $(\mathrm{RR}=13.7 ; P<0.001)$. Neither humidity nor temperature was associated with whether the calf was in or out of the hutch or whether they were standing or lying $(P>0.70)$.

Respiratory rates ranged from 24 to 108 breaths per minute across the morning and late afternoon observation periods (mean $=46$ ). Of the 60 respiratory rate observations made, $37(62 \%)$ were greater than the normal range of 24 to 36 . Respiratory rate was linearly related to internal hutch temperature but not humidity. For every $1^{\circ} \mathrm{C}$ increase in internal hutch temperature, respiratory rate increased by 2 breaths per minute $\left(\mathrm{R}^{2}=0.22 ; P=0.005\right)$. Overall, respiratory rates were higher, on average, if the calf was observed in the hutch or lying (48 vs. 39 breaths per minute; $P$ $=0.04)$. To evaluate the effect of elevating the hutch, respiratory rates were compared at the morning (0700 h) and evening $(1700 \mathrm{~h})$ time periods. Across both time periods, hutch elevation resulted in lower respiratory 

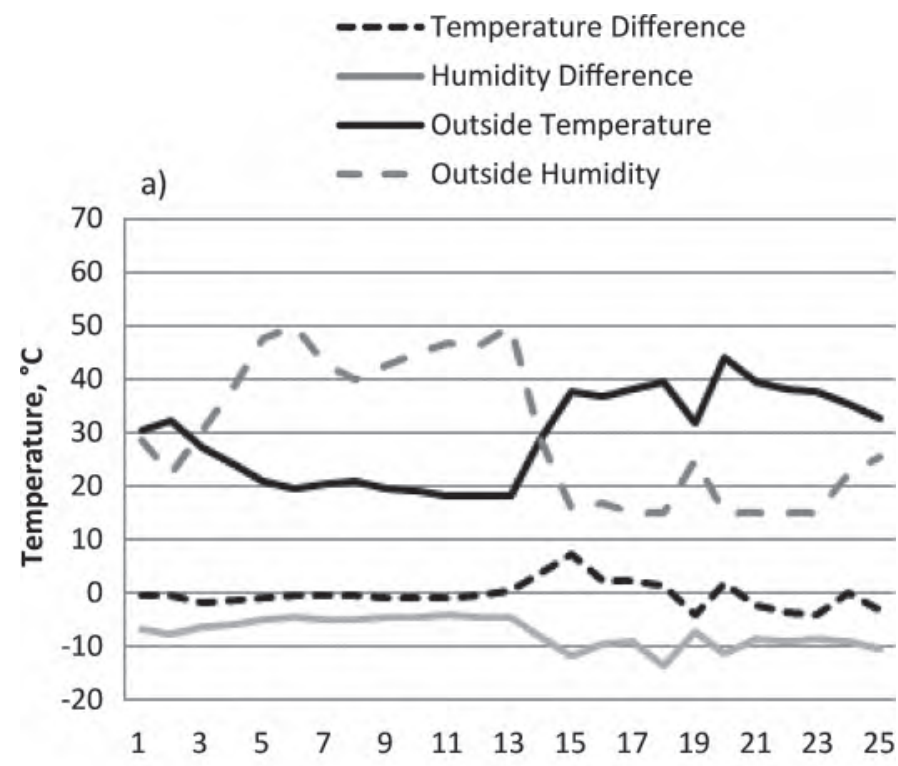

b)

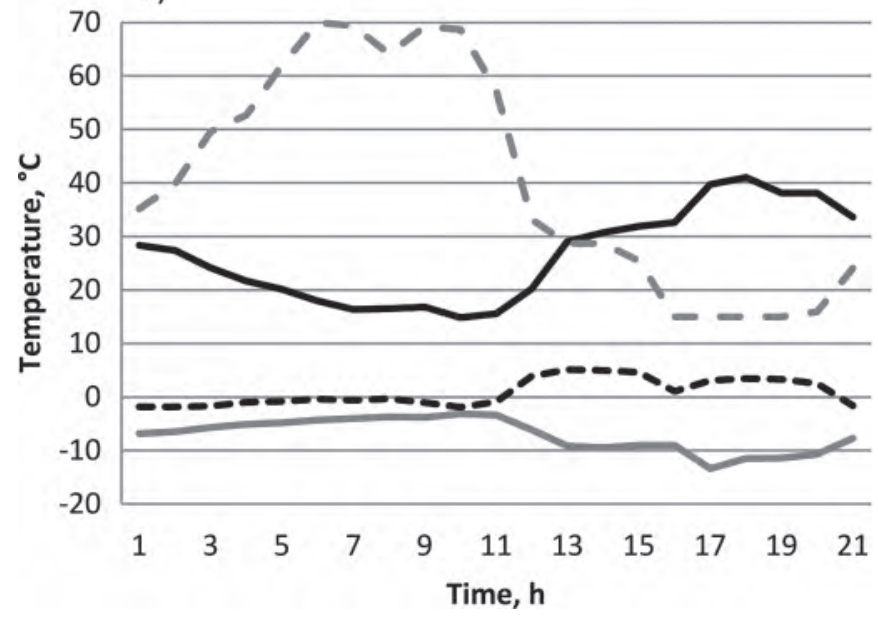

Figure 2. Hourly average temperature $\left({ }^{\circ} \mathrm{C}\right)$ and humidity (\%) inside preweaned plastic calf hutches over 2 time periods (starting time 1 was $1720 \mathrm{~h}$ ), without (a) and with (b) hutch elevation.

rates (paired $t$-test; $P=0.001$ ), but when evaluating respiratory rate differences at each of the 2 different time periods, only the late afternoon $(1700 \mathrm{~h})$ had significantly lower respiratory rates with the hutch elevated (44 vs. 58 breaths per minute; $P=0.0004$ ). One possible reason for this is that $93 \%$ of calves were standing at the morning observation period without hutch elevation compared with $100 \%$ of all calves lying at the same time period when the hutch was elevated, indicating that body position or location (or both) of the calf might have contributed to the variation seen in respiratory rates. However, in the Spain and Spiers (1996) study of shade cloth over hutches, respiratory rates were similarly not significantly reduced by shade

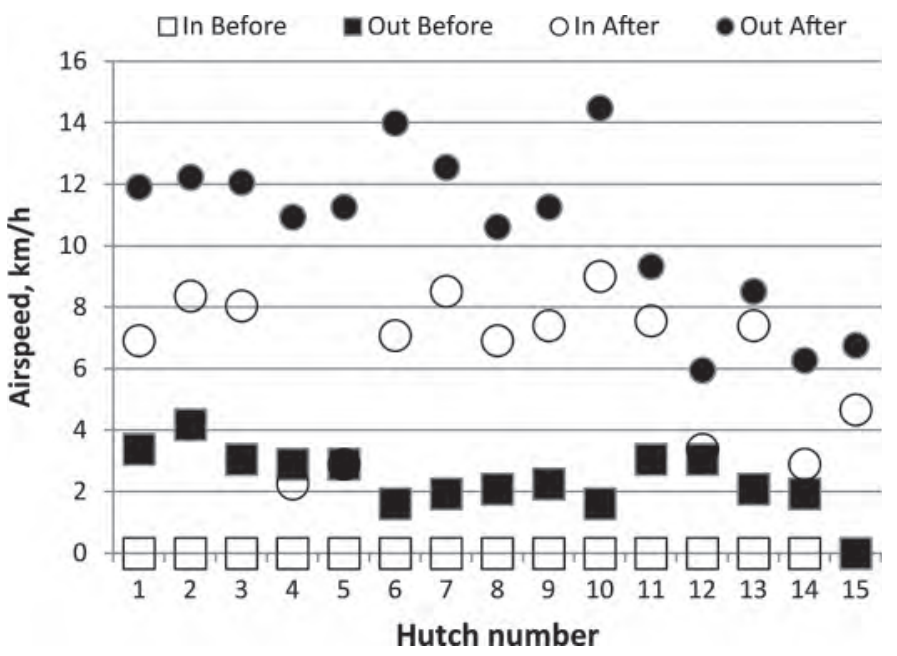

Figure 3. Airspeed $(\mathrm{km} / \mathrm{h})$ inside and outside 15 plastic calf hutches before and after the placement of a concrete block at the back of the hutch.

in the morning (from 28 to 26 breaths per minute) but significantly reduced in the afternoon (from 58 to 47 breaths per minute).

Producers using individual calf hutches have choices to improve calf welfare by mitigating heat and improving the hutch environment. Probably the best evidenced-based measure to reduce heat stress for hutch housing is to provide supplemental shade, such as shade cloth over the hutches, which is associated with lower hutch temperatures (about $2-7^{\circ} \mathrm{C}$ ) and reduced respiratory rates (Coleman et al., 1996; Spain and Spiers, 1996; Eigenberg et al., 2005). Orienting hutches to the north in hot US climates might also help maximize shade for calves. In addition, as a result of our study, some evidence exists for the benefits of elevating a calf hutch with a concrete block in summer. Elevation of a

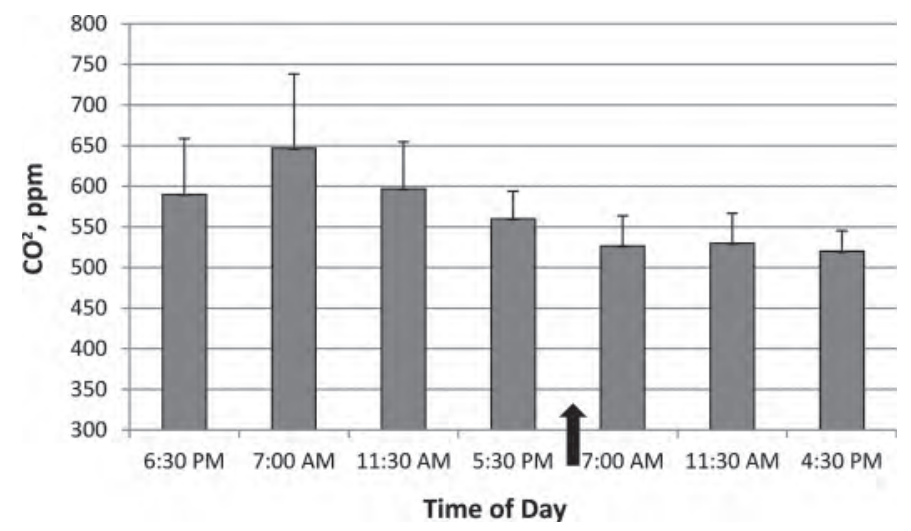

Figure 4. Average hutch internal $\mathrm{CO}_{2}$ levels (ppm) before and after a concrete block was placed to elevate plastic calf hutches, noted at the black arrow. 
sand-bedded calf hutch was previously shown to reduce airborne bacterial counts presumably by increasing the number of air turnovers per hour (Hill et al., 2011). Although the Hill study only elevated hutches by $4 \mathrm{~cm}$, similar or perhaps greater effects could be expected using a larger block such as the ones used in our trial. We saw that without hutch elevation, there is little to no air movement inside. The block allowed for some movement of air, as evidenced by airspeed and a reduction in hutch carbon dioxide levels. Further research could examine effects on heat stress remediation with different hutch designs, such as those with larger vent openings or added shade at the hutch level.

\section{ACKNOWLEDGMENTS}

We thank the dairy owner and employees for allowing us to conduct this trial on their operation and Katy Heaton (Dept. Veterinary Clinical Sciences, Washington State University, Pullman) for technical assistance.

\section{REFERENCES}

Broucek, J., P. Kisac, and P. Uhrincat. 2009. Effect of hot temperatures on the hematological parameters, health, and performance of calves. Int. J. Biometeorol. 53:201-208.

Coleman, D. A., B. R. Moss, and T. A. McCaskey. 1996. Supplemental shade for dairy calves reared in commercial calf hutches in a southern climate. J. Dairy Sci. 79:2038-2043.

De Sousa, P., and S. Pedersen. 2004. Ammonia emission from fattening pig houses in relation to animal activity and carbon dioxide production. Agric. Eng. Intl. 6:BC04 003. Accessed Jan. 30, 2012. http://www.cigrjournal.org/index.php/Ejounral/article/ view $/ 547 / 541$

Eigenberg, R. A., T. M. Brown-Brandl, J. A. Nienaber, and G. L. Hahn. 2005. Dynamic response indicators of heat stress in shaded and non-shaded feedlot cattle, Part 2: Predictive relationships. Biosystems Eng. 91:111-118.

Gebremedhin, K. G., C. O. Cramer, and W. P. Porter. 1981. Predictions and measurements of heat production and food and water requirements of Holstein calves in different environments. Trans. Am. Soc. Agric. Eng. 24:715-720.
Heinrichs, A. J., B. S. Heinrichs, O. Harel, G. W. Rogers, and N. T. Place. 2005. A prospective study of calf factors affecting age, body size, and body condition score at first lactation. J. Dairy Sci. 88:2828-2835.

Hill, T. M., H. G. Bateman, J. M. Aldrich, and R. L. Schlotterbeck. 2011. Comparisons of housing, bedding, and cooling options for dairy calves. J. Dairy Sci. 94:2138-2146.

Lamb, R. C., B. K. Morrow, M. Arambel, and C. W. Arave. 1987. Comparison of plastic domes with wooden hutches for housing dairy calves. J. Dairy Sci. 70(Suppl. 1):145.

Lammers, B. P., J. W. vanKoot, A. J. Heinrichs, and R. E. Graves 1996. The effect of plywood and polyethylene calf hutches on heat stress. Appl. Eng. Agric. 12:741-745.

Moore, D., K. Heaton, S. Poisson, and W. M. Sischo. 2010. Effects of hutch or pen environment on pre-weaned calf health, welfare, and performance. Veterinary Medicine Extension, Washington State University, Pullman. Accessed June 10, 2011. http://extension. wsu.edu/vetextension/calfscience/Documents/CalfEnv4-EnvironmentEffects.pdf.

Morrill, J. L., J. R. Dunham, and E. P. Call. 1991. Raising dairy heifers. Cooperative Extension Service, Kansas State University, Manhattan. Accessed Oct. 10, 2011. http://www.ksre.ksu.edu/library/ lvstk2/c721.pdf.

Neuwirth, J. G., J. K. Norton, C. A. Rawlings, F. N. Thompson, and G. O. Ware. 1979. Physiologic responses of dairy calves to environmental heat stress. Int. J. Biometeorol. 23:243-254.

Prill, R. 2000. Why measure carbon dioxide inside buildings? Washington State University Extension Energy Program, Spokane. Accessed Jun. 10, 2011. http://www.energy.wsu.edu/Documents/ CO2inbuildings.pdf.

Radostits, O. M., I. G. Mayhew, and D. M. Houston. 2000. Clinical examination of cattle and calves. Page 158 in Veterinary Clinical Examination and Diagnosis. W. B. Saunders, London, UK.

Spain, J. N., and D. E. Spiers. 1996. Effects of supplemental shade on thermoregulatory response of calves to heat challenge in a hutch environment. J. Dairy Sci. 79:639-646.

Stott, G. H., F. Wiersma, B. E. Menefee, and F. R. Radwanski. 1976. Influence of environment on passive immunity of calves. J. Dairy Sci. 59:1306-1311.

Tyson, J. 2011. Calves and heat stress. College of Agricultural Sciences, Penn State, University Park. Accessed Dec. 10, 2011. http:// www.das.psu.edu/research-extension/dairy/capitalregion/newsletter/articles/df-201008-03.

Wathes, C. M., K. Howard, C. D. R. Jones, and A. J. F. Webster. 1984. The balance of airborne bacteria in calf houses. J. Agric. Eng. Res. 30:81-90. 